Check for updates

Cite this: Chem. Sci., 2020, 11, 551

- All publication charges for this article have been paid for by the Royal Society of Chemistry

Received 7th October 2019

Accepted 23rd November 2019

DOI: $10.1039 /$ c9sc05026d

rsc.li/chemical-science

\section{Reduction of a dihydroboryl cation to a boryl anion and its air-stable, neutral hydroboryl radical through hydrogen shuttling $\dagger$}

\author{
Stephan Hagspiel, ${ }^{\text {ab }}$ Merle Arrowsmith, (D) ab Felipe Fantuzzi, (D) abc \\ Alexander Hermann, ${ }^{\text {ab }}$ Valerie Paprocki, ${ }^{\text {ab }}$ Regina Drescher, ${ }^{\text {ab }}$ Ivo Krummenacher ${ }^{\text {ab }}$ \\ and Holger Braunschweig (D)*ab
}

\begin{abstract}
The addition of Lewis bases to a cyclic (alkyl)(amino)carbene (CAAC)-supported dihydroboron triflate yields the mixed doubly base-stabilised dihydroboryl cations $\left[(\mathrm{CAAC}) \mathrm{BH}_{2} \mathrm{~L}\right]^{+}$. Of these, $\left[(\mathrm{CAAC})_{2} \mathrm{BH}_{2}\right] \mathrm{OTf}(\mathrm{OTf}=$ triflate) underwent facile two-electron reduction with $\mathrm{KC}_{8}$ owing to a 1,2-hydride migration from boron to the carbene carbon to yield a stable hydroboryl anion. One-electron oxidation of the latter yielded the first neutral hydroboryl radical, which is bench-stable in the solid state.
\end{abstract}

\section{Introduction}

Cyclic (alkyl)(amino)carbenes (CAACs) have become the ligands of choice for the stabilisation of many main group compounds in low oxidation states owing to their excellent $\sigma$-donor and $\pi$ acceptor properties derived from a relatively high-lying HOMO and low-lying LUMO..$^{1-4}$ In the field of low-valent mononuclear boron chemistry, they have been successfully employed to synthesise unusual boron(II) species such as boryl radicals ([(CAAC) $\mathrm{BXY}]^{\circ} ; \mathrm{X}, \mathrm{Y}=$ anionic ligands, e.g. I, Fig. 1a), ${ }^{5-10}$ boryl radical cations $\left([(\mathrm{CAAC}) \mathrm{LBY}]^{++}, \mathrm{L}=\text { Lewis donor }\right)^{10-13}$ and boryl anions ([(CAAC)BXY $]^{-}$, e.g. II $),{ }^{14-17}$ as well as boron(I) species such as borylenes ((CAAC)LBX, e.g. III, and (CAAC)BNR 2$){ }^{6-8,11-13,16,18-20}$ In all these compounds, the accumulation of negative charge on the low-valent boron centre is stabilised through $\pi$ backbonding to the CAAC ligand(s) (Fig. 1a), making many of them surprisingly stable under inert conditions. ${ }^{1-4}$ Recently, transient dicoordinate (CAAC)-stabilised borylenes have drawn particular attention as compounds capable of activating and catenating $\mathrm{N}_{2},{ }^{21-25}$ the latter reaction being unprecedented even in transition metal chemistry.

Furthermore, CAACs have been shown to activate elementhydrogen $\sigma$ bonds, including $\mathrm{H}-\mathrm{H}, \mathrm{N}-\mathrm{H}, \mathrm{P}-\mathrm{H}, \mathrm{Si}-\mathrm{H}$ and $\mathrm{B}-\mathrm{H}$ by addition to their nucleophilic carbene carbon. ${ }^{3,4}$ In CAAC-

${ }^{a}$ Institut für Anorganische Chemie, Julius-Maximilians-Universität Würzburg, Am Hubland, 97074 Würzburg, Germany.E-mail: h.braunschweig@uni-wuerzburg.de

${ }^{b}$ Institute for Sustainable Chemistry \& Catalysis with Boron, Julius-MaximiliansUniversität Würzburg, Am Hubland, 97074 Würzburg, Germany

'Institut für Physikalische und Theoretische Chemie, Julius-Maximilians-Universität Würzburg, Emil-Fischer-Straße 42, 97074 Würzburg, Germany

$\dagger$ Electronic supplementary information (ESI) available: Synthetic procedures, NMR, EPR, UV-vis, IR, CV, X-ray crystallographic data and details of the computational analyses. CCDC 1956847-1956854. For ESI and crystallographic data in CIF or other electronic format see DOI: 10.1039/c9sc05026d supported hydroboron compounds, the B-H bond activation process can be reversible (Fig. 1b) 1 14,26,27 and is favoured by electron-donating ligands at boron, ${ }^{8,26-30}$ thereby affording additional stabilisation for electron-rich lower oxidation state species through facile hydrogen shuttling. In this contribution we combine the excellent $\sigma$-donating $/ \pi$-accepting and $\mathrm{B}-\mathrm{H}$ bond activating properties of CAACs to synthesise and isolate a solvent-free alkyl(hydro)boryl anion, and selectively oxidise it to the corresponding radical, which is surprisingly air-stable in the solid state.

\section{Results and discussion}

Following a procedure by Bertrand and co-workers, ${ }^{12}$ methyl trifluoromethanesulfonate (MeOTf) was employed to abstract a hydride from $\left(\mathrm{CAAC}^{\mathrm{Me}}\right) \mathrm{BH}_{3} \quad\left(\mathrm{CAAC}^{\mathrm{Me}}=1-(2,6-\right.$ diisopropylphenyl)-3,3,5,5-tetramethylpyrrolidin-2-ylidene).

The resulting triflate derivative 1 was treated in a $1: 1$ ratio with a series of Lewis bases in benzene to generate the bis(base)stabilised boronium cations $\left[\left(\mathrm{CAAC}^{\mathrm{Me}}\right) \mathrm{BH}_{2} \mathrm{~L}\right] \mathrm{OTf} \quad(2-\mathrm{L}, \mathrm{L}=$ $\mathrm{CAAC}^{\mathrm{Me}}, \quad \mathrm{IMe}^{\mathrm{Me}}=1,3$-dimethylimidazol-2-ylidene, $\mathrm{PMe}_{3}$, Scheme 1a), all presenting a characteristic upfield ${ }^{11} \mathrm{~B} N M R B \mathrm{H}_{2}$ triplet in the -22 to $-30 \mathrm{ppm}$ region. $\S$ In the case of the 4dimethylaminopyridine (DMAP) derivative, 2-DMAP $\left(\delta_{11_{\mathrm{B}}}=\right.$ $-10.6 \mathrm{ppm}$, broad), the synthesis had to be carried out in THF as treatment of 1 with one equivalent of DMAP in benzene resulted in the formation of the bis(DMAP) adduct 3-DMAP $\left(\delta^{1{ }^{1} \mathrm{~B}}\right.$ $=4.2 \mathrm{ppm}$, Scheme $1 \mathrm{~b}$ ), in which the second DMAP equivalent has promoted a typical 1,2-migration of one hydrogen atom from boron to the CAAC ${ }^{\mathrm{Me}}$ ligand. ${ }^{26}$ The solid-state structure of 3-DMAP (Fig. 2) evidences the binding of the DMAP residues and the migration of $\mathrm{H} 1$ to $\mathrm{C} 1$, which is now $\mathrm{sp}^{3}$-hybridised (B1C1 1.619(4), C1-N1 1.490(3) ̊). In contrast, the binding of a second equivalent of pyridine to $2-\mathrm{Pyr}\left(\delta_{11_{\mathrm{B}}}=-9.3 \mathrm{ppm}\right.$, 
a) Examples of CAAC-stabilised $B(I I)$ and $B(I)$ species

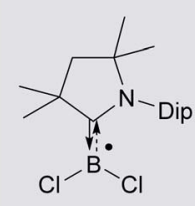

boryl radical (I)

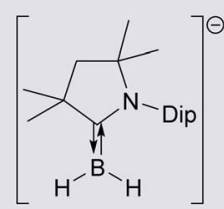

boryl anion (II)

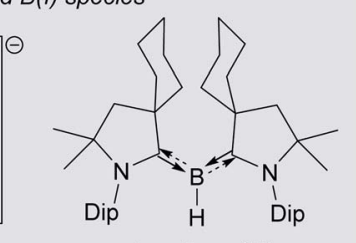

borylene (III) b) Example of reversible $B$-to-CAAC hydrogen shuttling

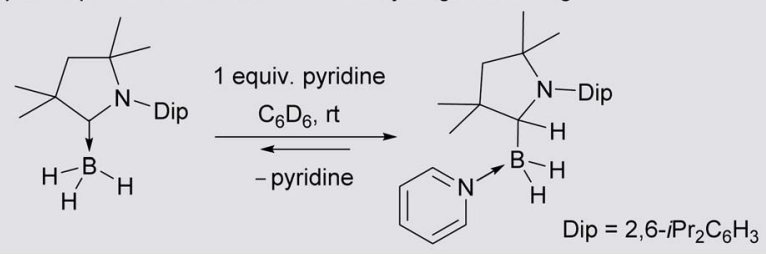

Fig. 1 (a) Selected examples of CAAC-stabilised $B(॥)$ and $B(।)$ species; (b) example of reversible Lewis-base-induced B-to-CAAC hydrogen shuttling.

broad) was found to be reversible: even in neat pyridine only $c a$. $75 \%$ conversion to $3-\mathbf{P y r}\left(\delta_{{ }^{11} \mathrm{~B}}=6.9 \mathrm{ppm}\right)$ was observed. The use of 4,4'-bipyridine as a base led to the formation of the $4,4^{\prime}$ bipyridine-bridged bis(boronium) species 4-Bipy $\left(\delta_{11} \mathrm{~B}=\right.$ $-8.6 \mathrm{ppm}$, broad, Scheme 1c). Attempts to synthesise the derivative 2-thf in THF resulted in ring-opening polymerisation of the solvent within two days at room temperature.

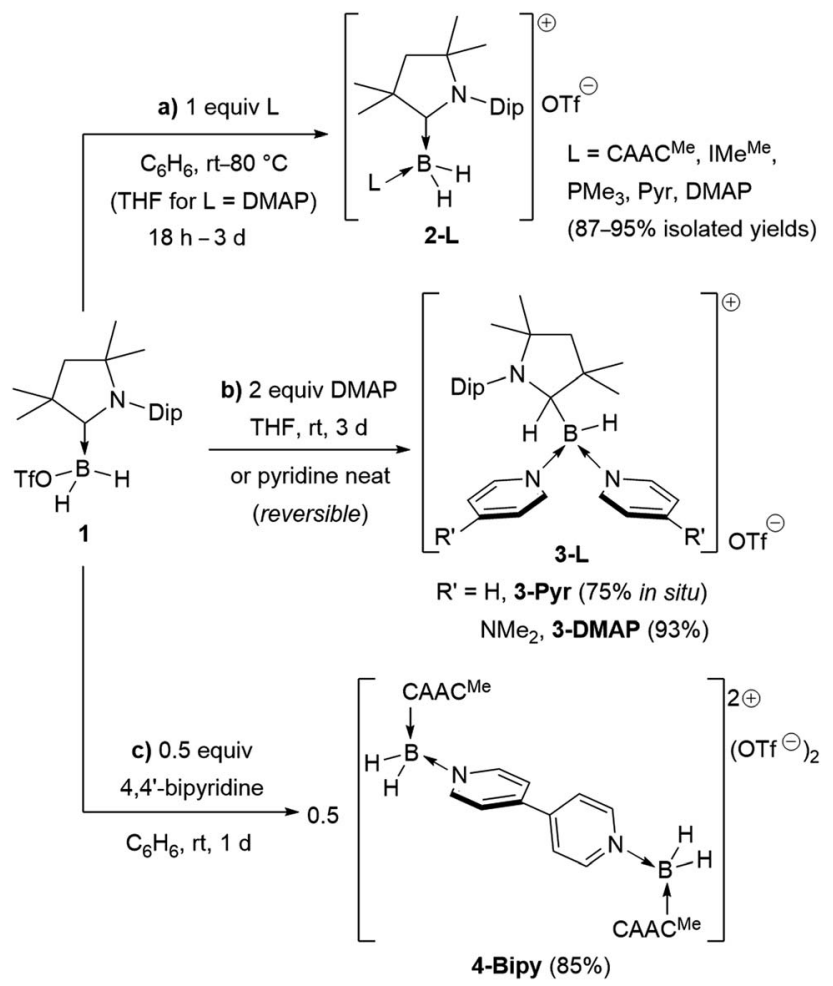

Scheme 1 Syntheses of bis- and tris(base)-stabilised boronium cations (a) 2-L, (b) 3-L and (c) 4-L. Isolated yields in brackets. $I \mathrm{Me}^{\mathrm{Me}}=$ 1,3,4,5-tetramethylimidazol-2-ylidene, $\mathrm{Pyr}=$ pyridine, $\mathrm{DMAP}=4$ dimethylaminopyridine.

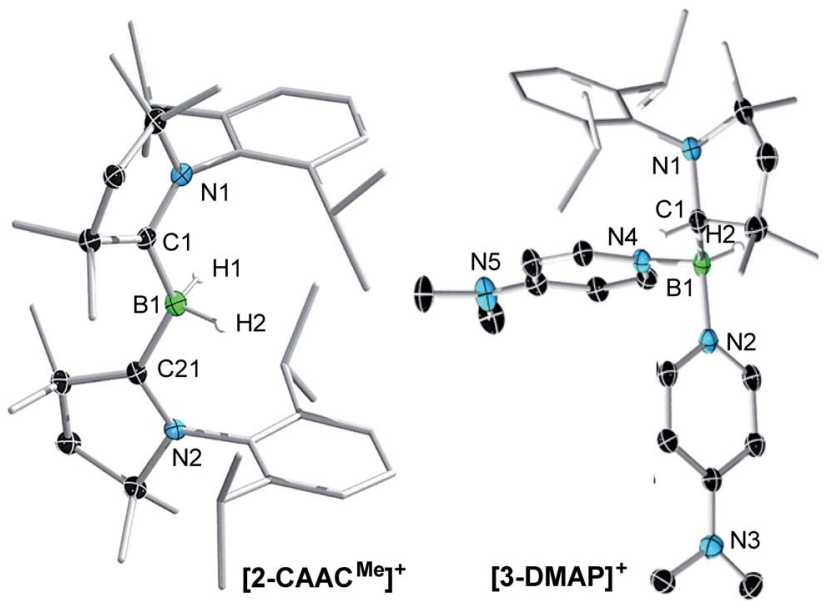

Fig. 2 Crystallographically derived molecular structures of the 2$\mathrm{CAAC}^{\mathrm{Me}}$ (one of the two crystallographically distinct cations present in the asymmetric unit) and 3-DMAP cations. Atomic displacement ellipsoids are set at $50 \%$ probability. Ellipsoids of $\mathrm{CH}_{3}$ and iPr groups, triflate counteranion and hydrogen atoms omitted for clarity except for boron-bound hydrides.t Selected bond lengths (Å) for 2-CAAC ${ }^{\mathrm{Me}}$. $\mathrm{B} 1-\mathrm{C} 1$ 1.597(7), B1-C21 1.607(7), B1-H1 1.11(6), B1-H2 1.16(6), C1-N1 1.316(6), C21-N2 1.310(6); for 3-DMAP B1-C1 1.619(4), B1-N2 1.585(3), B1-N4 1.597(3), B1-H2 1.10(2), C1-N1 1.490(3).

Attempts to reduce 2-L, 3-L and 4-L under various conditions all resulted in unselective reactions, except for 2-CAAC ${ }^{\mathbf{M e}}$, which was readily reduced with excess $\mathrm{KC}_{8}$ to the red-coloured (alkyl) hydroboryl anion 5 by 1,2-migration of one hydrogen atom from boron to $\mathrm{CAAC}^{\mathrm{Me}}$ (Scheme $2 \mathrm{a}$ ). The ${ }^{11} \mathrm{~B}$ NMR spectrum of 5

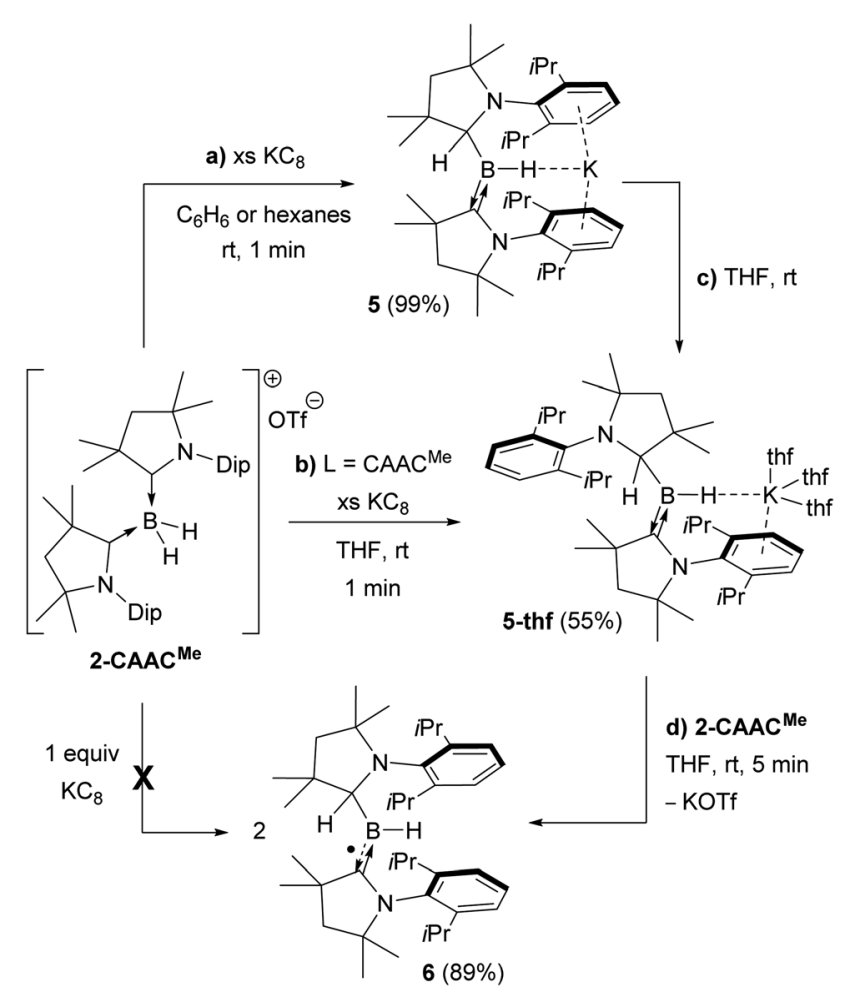

Scheme 2 Reduction of 2-CAAC ${ }^{\text {Me }}$ to boryl anions (a) 5 and (b) - (c) 5thf, and subsequent comproportionation to (d) boryl radical 6 . 

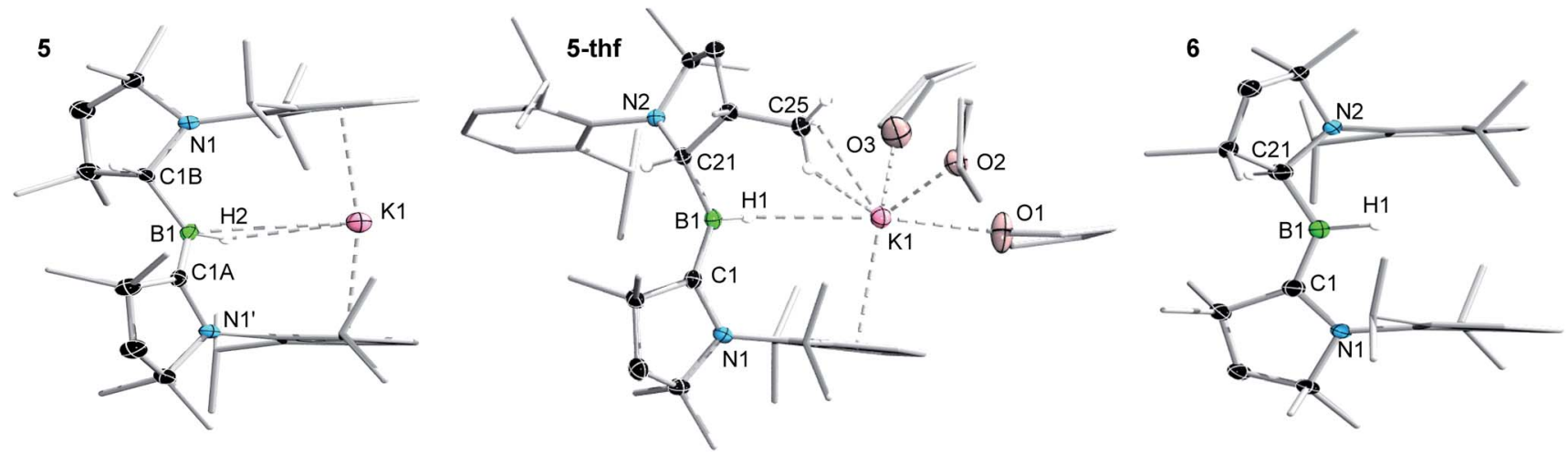

Fig. 3 Crystallographically derived molecular structures of 5, 5-thf and 6 . Atomic displacement ellipsoids are set at 50\% probability. Ellipsoids of $\mathrm{CH}_{2}, \mathrm{CH}_{3}$ and iPr groups and hydrogen atoms omitted for clarity except for boron-bound hydrides. Selected bond lengths $(\AA)$ and angles $\left({ }^{\circ}\right)$ for

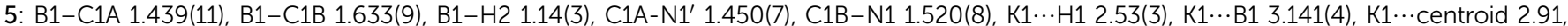
$\Sigma \angle B 1359.4(12), \Sigma \angle C 1 A$ 359.7(5), B1-H2-K1 111.8(12); for 5-thf: B1-C1 1.452(2), B1-C21 1.620(2), B1-H1 1.159(17), C1-N1 1.4601(18), C21-N2

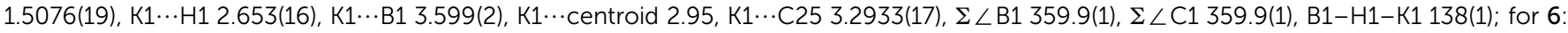
B1-C1 1.5174(18), B1-C21 1.5817(18), B1-H1 1.142(18), C1-N1 1.3777(15), C21-N2 1.4616(15), $\Sigma \angle B 1359.5(6), \Sigma \angle C 1359.6(1)$.

shows a single broad resonance at $16.7 \mathrm{ppm}$, significantly downfield-shifted from that of other CAAC-stabilised boryl anions, which range from $\delta^{11_{\mathrm{B}}}=-4.7 \mathrm{ppm}$ for $\left[\left(\mathrm{CAAC}^{\mathrm{Me}}\right) \mathrm{BH}_{2}\right]^{-}$ to $\delta^{{ }_{11} \mathrm{~B}}=-17.9 \mathrm{ppm}$ for $\left[\left(\mathrm{CAAC}^{\mathrm{Cy}}\right) \mathrm{B}(\mathrm{CN})_{2}\right]^{-}{ }^{14-17}$ likely because of the electron-withdrawing nature of the aminoalkyl substituent $\mathrm{CAAC}^{\mathrm{Me}} \mathrm{H}$. The ${ }^{1} \mathrm{H}\left\{{ }^{11} \mathrm{~B}\right\}$ NMR spectrum shows a $\mathrm{B} H$ doublet at $1.90 \mathrm{ppm}\left({ }^{3} J=6.6 \mathrm{~Hz}\right)$, coupling to the $\mathrm{BC} H$ resonance of the $\mathrm{CAAC}^{\mathrm{Me}} \mathrm{H}$ ligand at $4.38 \mathrm{ppm}$, as well as two sets of unsymmetrical CAAC ${ }^{\mathrm{Me}}$ ligand resonances. An X-ray crystallographic analysis revealed a monomeric structure with a trigonal-planar boron atom $\left(\Sigma \angle \mathrm{B} 1359(1)^{\circ}\right)$, in which the potassium cation bound to the $\mathrm{B} H$ hydride $(\mathrm{K} 1 \cdots \mathrm{H} 22.53(3) \AA)$ is encapsulated by the ligand sphere through $\eta^{6}-\pi$ interactions with the Dip $(=2,6-$ diisopropylphenyl) substituents of the CAAC ${ }^{\mathrm{Me}}$ and $\mathrm{CAAC}^{\mathrm{Me}} \mathrm{H}$ ligands (Fig. 3). The B1-C1A bond length of 1.439(11) $\AA$ is significantly shorter than in the $\mathbf{2}$-CAAC ${ }^{\mathbf{M e}}$ precursor $\left(\mathrm{B}-\mathrm{C}_{\text {avg. }}\right.$. $1.69 \AA$, Fig. 2) and typical of a $\mathrm{B}=\mathrm{C}$ double bond. This is indicative of strong $\pi$ backdonation from the lone pair of the boryl anion to the $\pi$-accepting CAAC $^{\mathrm{Me}}$ ligand, as found in all CAAC-stabilised boryl anions. ${ }^{6,14-17}$ According to DFT calculations carried out at the $\omega \mathrm{B} 97 \mathrm{XD} / 6-31+\mathrm{G}^{*}$ level of theory, the HOMO of 5 possesses $\pi$-bonding character between B1 and $\mathrm{C} 1 \mathrm{~A}$, with a nodal plane located at the C1A-N1' bond region (Fig. 4). As in 3-DMAP, a 1,2-hydride shift has occurred and C1B is now sp ${ }^{3}$-hybridised (B1-C1B 1.633(9), N1-C1B 1.520(8) Å). The presence of the hydrogen atom at boron was further confirmed by a solid-state infrared absorption at $2329 \mathrm{~cm}^{-1}$, corresponding to the $\mathrm{B}-\mathrm{H}$ stretching mode. The computed $\mathrm{B}-\mathrm{H}$ stretching mode of $2352 \mathrm{~cm}^{-1}$ at $\omega \mathrm{B} 97 \mathrm{XD} / 6-31+\mathrm{G}^{*}$ agrees well with the experimental value.

The reduction of 2-CAAC ${ }^{\mathrm{Me}}$ in THF or the dissolution of 5 in THF both yielded the analogue 5-thf (Scheme 2b, c and Fig. 3), in which the hydride-bound potassium cation is $\eta^{6}-\pi$-stabilised now only by the Dip substituent of the neutral CAAC ${ }^{\mathrm{Me}}$ ligand, its coordination sphere being completed by three THF molecules and an agostic interaction with one of the vicinal methyl groups (C25) of the $\mathrm{CAAC}^{\mathrm{Me}} \mathrm{H}$ ligand. The bond lengths and
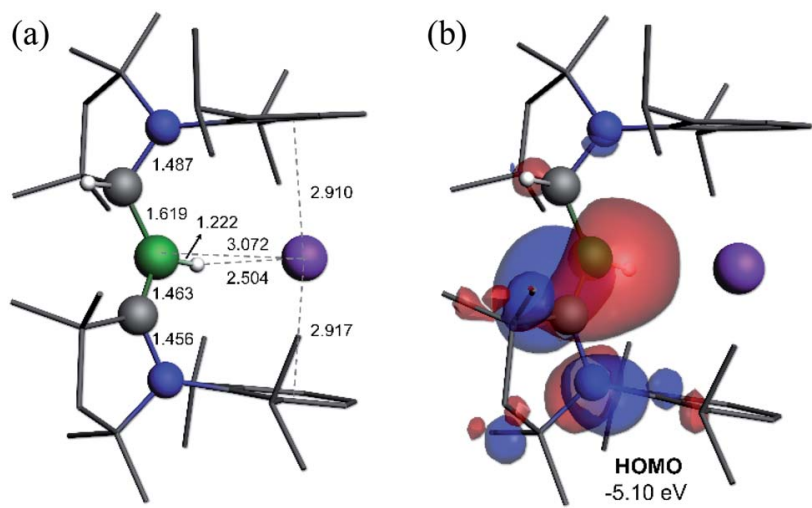

Fig. 4 (a) Calculated structure of 5 at the $\omega B 97 X D / 6-31+G *$ level of theory. (b) Plot of the HOMO of 5 ( $\omega B$ B $7 X D / 6-311++G * *)$.

angles of the boryl anion core change little compared to those of solvent-free $\mathbf{5}$, the major difference being the conformation of the pyrrolidine rings of $\mathrm{CAAC}^{\mathrm{Me}} \mathrm{H}$ and $\mathrm{CAAC}^{\mathrm{Me}}$, which flip so that the Dip substituents now point in opposite directions.

Cyclic voltammograms of 2-CAAC ${ }^{\text {Me }}$ and 5-thf in THF $(0.1 \mathrm{M}$ $\left.\left[n \mathrm{Bu}_{4} \mathrm{~N}\right]\left[\mathrm{PF}_{6}\right]\right)$ were essentially identical, showing a reversible redox event at $E_{1 / 2}=-2.31 \mathrm{~V}$ and an irreversible oxidation around $-0.90 \mathrm{~V}$ (relative to $\mathrm{Fc} / \mathrm{Fc}^{+}$), suggesting that chemical oxidation of 5 to 6 should be possible. Indeed, the reaction of 5thf with 2-CAAC ${ }^{\mathrm{Me}}$ led to quantitative comproportionation to the boryl radical 6 (Scheme 2d). Attempts to generate 6 by the direct one-electron reduction of 2-CAAC ${ }^{\text {Me }}$ failed, resulting instead in incomplete consumption of 2-CAAC ${ }^{\mathbf{M e}}$ and generating a mixture of $\mathbf{5}$ and $\mathbf{6}$. Radical $\mathbf{6}$ is deep purple in solution $\left(\lambda_{\max }=523 \mathrm{~nm}\right.$ in the UV-vis spectrum) and ${ }^{11} \mathrm{~B}$ NMR-silent. In the solid state, however, isolated crystals of 6 are deep orange. $\mathrm{X}$-ray diffraction analysis showed a structure very similar to 5 bar the potassium cation, with a trigonal planar B1 centre $\left(\Sigma \angle \mathrm{B} 1359.5(6)^{\circ}\right)$ and the Dip groups of the $\mathrm{CAAC}^{\mathrm{Me}} \mathrm{H}$ and $\mathrm{CAAC}^{\mathrm{Me}}$ ligands both pointing in the same direction (Fig. 3). 
Unlike in 5 and 5-thf, the B1-C1 and C1-N1 bonds at the neutral CAAC $^{\mathrm{Me}}$ ligand (1.5174(18) and 1.4601(18) Å, respectively) are within the range typical of partial double bonds, as is typical for CAAC-stabilised boryl radicals due to the delocalisation of the unpaired electron over the N1-C1-B1 $\pi$ framework..$^{5-9,21,22,31-33}$

The IR spectrum of 6 shows a B-H stretching band at $2533 \mathrm{~cm}^{-1}$ (calc.: $2558 \mathrm{~cm}^{-1}$ at $\omega \mathrm{B} 97 \mathrm{XD} / 6-31+\mathrm{G}^{*}$ ), $c a .200$ wavenumbers higher than that in 5, and 100 higher than in Bertrand's hydroborylene III (Fig. 1a, $\nu(B-H)=2455 \mathrm{~cm}^{-1}$ ), suggesting a significant strengthening of the $\mathrm{B}-\mathrm{H}$ bond in radical 6 . The EPR spectrum of 6 displays a broad triplet from the hyperfine coupling to the ${ }^{14} \mathrm{~N}$ nucleus $\left(a_{{ }^{14} \mathrm{~N}}=18.5 \mathrm{MHz}\right.$, Fig. 5a). The simulated spectrum further provides hyperfine coupling parameters to the quadrupolar ${ }^{11} \mathrm{~B}$ nucleus $\left(a^{1{ }^{11}} \mathrm{~B}=9.7\right.$ $\mathrm{MHz}$ ), which is responsible for the line-broadening, and the $\mathrm{BH}$ and $\mathrm{CAAC}^{\mathrm{Me}} \mathrm{H}^{1} \mathrm{H}$ nuclei $\left(a_{{ }^{1} \mathrm{H}}=13.6\right.$ and $4.8 \mathrm{MHz}$, respectively). The presence of two distinct couplings to these ${ }^{1} \mathrm{H}$ nuclei suggests that the compound displays no fluxional B-to-CAAC hydrogen migration in solution.

Calculations show that the SOMO consists mainly of the B1C1 $\pi$ bond with some $\pi$-antibonding character on the C1-N1 bond (Fig. 5c). The calculated Mulliken atomic spin densities are $53 \%$ on $\mathrm{C} 1,21 \%$ on $\mathrm{N} 1$ and only $15 \%$ on $\mathrm{B} 1$, showing that the unpaired electron is mainly delocalised on the CAAC ligand (Fig. 5d), as already suggested by the much stronger EPR hyperfine coupling to $\mathrm{N} 1$ than $\mathrm{B} 1$ (vide supra). To our knowledge, 6 is the first example of a neutral, structurally characterised hydroboryl radical. Moreover, to our surprise, isolated
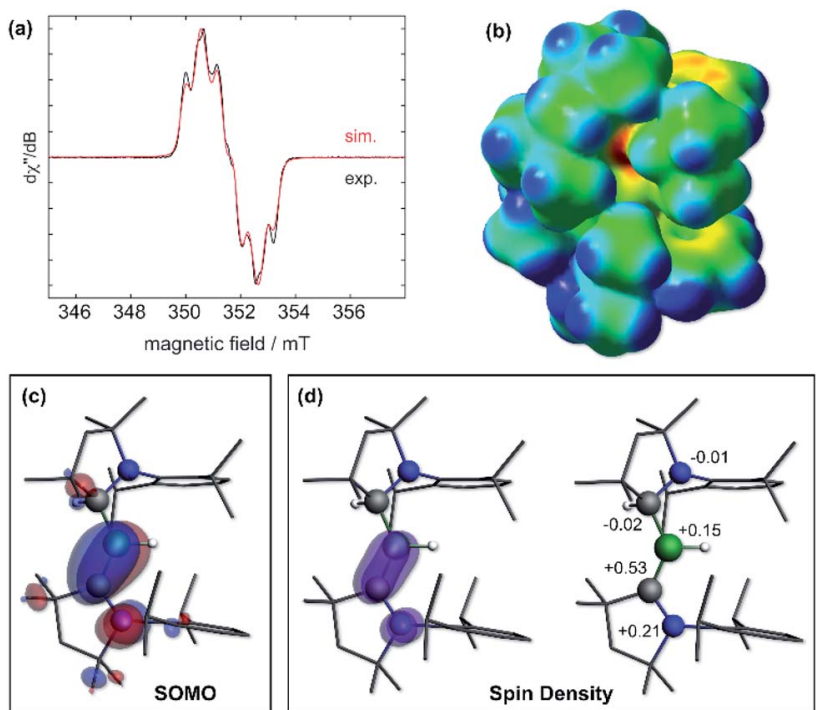

Fig. 5 (a) Experimental (black solid line) and simulated (red line) continuous-wave X-band EPR spectra of 6 in hexane solution at rt. Simulation parameters: $g_{\text {iso }}=2.0027, a\left({ }^{11} \mathrm{~B}\right)=9.7 \mathrm{MHz}, a\left({ }^{14} \mathrm{~N}\right)=18.5$ $\mathrm{MHz}, a\left({ }^{1} \mathrm{H}_{(\mathrm{H} 1)}\right)=13.6 \mathrm{MHz}$ and $a\left({ }^{1} \mathrm{H}_{(\mathrm{H} 21)}\right)=4.8 \mathrm{MHz}$; (b) electrostatic potential (ESP) map of 6 at the $\omega \mathrm{B} 97 \mathrm{XD} / 6-31+\mathrm{G} *$ level of theory. ESP charges following the notation of Fig. 3: N2: $-0.46, \mathrm{C} 21$ : $-0.01, \mathrm{~B} 1$ : $+0.19, \mathrm{H} 1:-0.17, \mathrm{C} 1:-0.27, \mathrm{N1}:-0.14$. (c) Plot of the SOMO of 6 (surface isovalue: $\pm 0.03\left[\mathrm{e} \mathrm{a}_{0}{ }^{-3}\right]^{1 / 2}$ ). (d) Left: plot of the calculated spin density of 6 (surface isovalue: $0.005\left[\mathrm{e} \mathrm{a}_{0}{ }^{-3}\right]$ ). Right: Mulliken atomic spin densities.

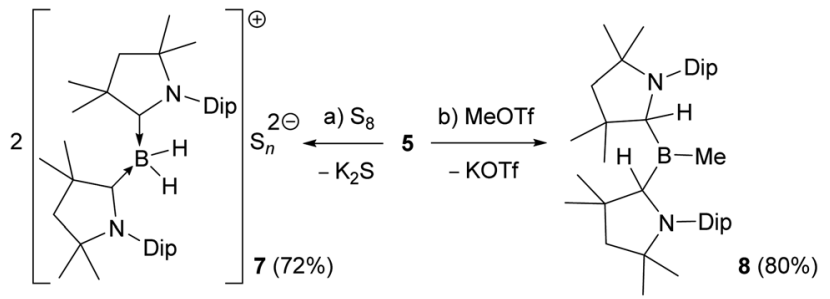

Scheme 3 (a) Reducing and (b) nucleophilic reactivity of boryl anion 5.

crystals of 6 proved air-stable at room temperature over a period of one week, making this compound a rare example of an airstable boron-centred radical. This is presumably owed to a combination of the high degree of spin delocalisation, the low spin density at boron and the very effective encapsulation of the $\mathrm{B}-\mathrm{H}$ unit by the $\mathrm{CAAC}^{\mathrm{Me}}$ and $\mathrm{CAAC}^{\mathrm{Me}} \mathrm{H}$ ligands as seen in the electrostatic potential map in Fig. 5b. The only other air-stable boron-based radical reported is a permethylated icosahedral borane $\left[\text { closo- } \mathrm{B}_{12}\left(\mathrm{CH}_{3}\right)_{12}\right]^{\cdot-}$ radical anion, in which the unpaired electron is trapped and delocalised within the $\mathrm{B}_{12}$ cage. $^{34}$

Reactions of the boryl anion 5 with a wide range of electrophiles including haloboranes, organohalides, heavier group 14 chlorides, as well as $\mathrm{Zn}$ (II), $\mathrm{Cu}(\mathrm{I})$ and $\mathrm{Au}(\mathrm{I})$ halides all resulted in quantitative oxidation of $\mathbf{5}$ to radical $\mathbf{6}$, and reduction of the corresponding electrophile. This contrasts with the boron nucleophile behaviour observed for CAAC-stabilised cyanoboryl anions. ${ }^{16,17}$ With elemental sulfur, double oxidation back to the 2-CAAC ${ }^{\text {Me }}$ cation was observed by NMR spectroscopic analysis $\left(\delta^{1{ }_{11} \mathrm{~B}}=-22.4 \mathrm{ppm}, t,{ }^{1} J_{11} \mathrm{~B}^{-1} \mathrm{H}=84.7 \mathrm{~Hz}\right)$, the counteranion presumably being a $\mathrm{S}_{n}{ }^{2-}$ polysulfide (7, Scheme 3a). The only nucleophilic reactivity observed was with methyl triflate, which yielded clean salt metathesis to the methylated trialkylborane $\mathbf{8}$ through migration of the second hydride to the remaining $\mathrm{CAAC}^{\mathrm{Me}}$ ligand $\left(\delta^{{ }^{11} \mathrm{~B}}=93.9 \mathrm{ppm}\right.$, Scheme $\left.3 \mathrm{~b}\right)$.

\section{Conclusions}

We have shown herein that the ability of CAACs to stabilise electron-rich boron centres and reversibly activate $\mathrm{B}-\mathrm{H}$ bonds can be harnessed together to reduce a $\left[\mathrm{L}_{2} \mathrm{BH}_{2}\right]^{+}$cation to $\mathrm{a}[\mathrm{LRBH}]^{-}$anion without the usual need for halide abstraction, thanks to B-to-CAAC hydrogen shuttling. This boryl anion reacts principally as a one-electron reducing agent to yield the neutral hydroboryl radical [LRBH] $]^{\circ}$, the surprising stability of which is ensured by the unique stereoelectronic properties of the two encapsulating $\mathrm{CAAC}^{\mathrm{Me}}$ ligands.

\section{Conflicts of interest}

The authors declare no conflict of interest.

\section{Acknowledgements}

The authors thank the Deutsche Forschungsgemeinschaft for financial support. S. H. is grateful for a doctoral fellowship from 
the Studienstiftung des Deutschen Volkes. F. F. thanks the Coordenação de Aperfeiçoamento de Pessoal de Nível Superior (CAPES) and the Alexander von Humboldt (AvH) Foundation for a Capes-Humboldt postdoctoral fellowship.

\section{Notes and references}

\$ The boron-bound hydrides of each structure were detected as residual electron density in the difference Fourier map and freely refined.

$\S$ The X-ray crystallographically-determined structures of 1, 2-Pyr and 2-DMAP can be found in the ESI, Fig. S55-S57.†

1 S. Kundu, S. Sinhababu, V. Chandrasekhar and H. W. Roesky, Chem. Sci., 2019, 10, 4727.

2 U. S. D. Paul, M. J. Krahfuß and U. Radius, Chem. Unserer Zeit, 2018, 53, 212.

3 M. Melaimi, R. J. M. Soleilhavoup and G. Bertrand, Angew. Chem., Int. Ed., 2017, 56, 10046.

4 M. Soleilhavoup and G. Bertrand, Acc. Chem. Res., 2015, 48, 256.

5 Y. Su and R. Kinjo, Coord. Chem. Rev., 2017, 352, 346.

6 M. Arrowsmith, J. I. Schweizer, M. Heinz, M. Härterich, I. Krummenacher, M. C. Holthausen and H. Braunschweig, Chem. Sci., 2019, 10, 5095.

7 H. Braunschweig, I. Krummenacher, M.-A. Légaré, A. Matler, K. Radacki and Q. Ye, J. Am. Chem. Soc., 2017, 139, 1802.

8 F. Dahcheh, D. Martin, D. W. Stephan and G. Bertrand, Angew. Chem., Int. Ed., 2014, 53, 13159.

9 P. Bissinger, H. Braunschweig, A. Damme, I. Krummenacher, A. K. Phukan, K. Radacki and S. Sugawara, Angew. Chem., Int. Ed., 2014, 53, 7360.

10 J.-S. Huang, W.-H. Lee, C.-T. Shen, Y.-F. Lin, Y.-H. Liu, S.-M. Peng and C.-W. Chiu, Inorg. Chem., 2016, 55, 12427.

11 S. Kumar Sarkar, M. M. Siddiqui, S. Kundu, M. Ghosh, J. Kretsch, P. Stollberg, R. Herbst-Irmer, D. Stalke, C. Stückl, B. Schwederski, W. Kaim, S. Ghorai, E. D. Jemmis and H. W. Roesky, Dalton Trans., 2019, 48, 8551.

12 D. A. Ruiz, M. Melaimi and G. Bertrand, Chem. Commun., 2014, 50, 7837.

13 R. Kinjo, B. Donnadieu, M. A. Celik, G. Frenking and G. Bertrand, Science, 2011, 333, 610.

14 M. Arrowsmith, J. D. Mattock, S. Hagspiel, I. Krummenacher, A. Vargas and H. Braunschweig, Angew. Chem., Int. Ed., 2018, 57, 15272.

15 M. Arrowsmith, J. D. Mattock, J. Böhnke, I. Krummenacher, A. Vargas and H. Braunschweig, Chem. Commun., 2018, 54, 4669.

16 M. Arrowsmith, D. Auerhammer, R. Bertermann, H. Braunschweig, M. A. Celik, J. Erdmannsdörfer,
I. Krummenacher and T. Kupfer, Angew. Chem., Int. Ed., 2017, 56, 11263.

17 D. A. Ruiz, G. Ung, M. Melaimi and G. Bertrand, Angew. Chem., Int. Ed., 2013, 52, 7590.

$18 \mathrm{~J}$. Böhnke, M. Arrowsmith and H. Braunschweig, J. Am. Chem. Soc., 2018, 140, 10368.

19 M. Arrowsmith, D. Auerhammer, R. Bertermann, H. Braunschweig, G. Bringmann, M. A. Celik, R. D. Dewhurst, M. Finze, M. Grüne, M. Hailmann, T. Hertle and I. Krummenacher, Angew. Chem., Int. Ed., 2106, 55, 14462.

20 M. Soleilhavoup and G. Bertrand, Angew. Chem., Int. Ed., 2017, 56, 10282.

21 M.-A. Légaré, M. Rang, G. Bélanger-Chabot, J. I. Schweizer, I. Krummenacher, R. Bertermann, M. Arrowsmith, M. C. Holthausen and H. Braunschweig, Science, 2019, 363, 1329.

22 M.-A. Légaré, G. Bélanger-Chabot, R. D. Dewhurst, E. Welz, I. Krummenacher, B. Engels and H. Braunschweig, Science, 2018, 359, 896.

23 M.-A. Légaré, C. Pranckevicius and H. Braunschweig, Chem. Rev., 2019, 119, 8231.

24 C. Hering-Junghans, Angew. Chem., Int. Ed., 2108, 57, 6738. 25 A. J. Ruddy, D. M. C. Ould, P. D. Newman and R. L. Melen, Dalton Trans., 2018, 47, 10377.

26 D. Auerhammer, M. Arrowsmith, H. Braunschweig, R. D. Dewhurst, J. O. C. Jiménez-Halla and T. Kupfer, Chem. Sci., 2017, 8, 7066.

27 M. Arrowsmith, J. Böhnke, H. Braunschweig and M. A. Celik, Angew. Chem., Int. Ed., 2017, 56, 14287.

28 S. Würtemberger-Pietsch, H. Schneider, T. B. Marder and U. Radius, Chem. -Eur. J., 2016, 22, 13032.

29 M. R. Momeni, E. Rivard and A. Brown, Organometallics, 2013, 32, 6201.

30 G. D. Frey, J. D. Masuda, B. Donnadieu and G. Bertrand, Angew. Chem., Int. Ed., 2010, 49, 9444.

31 A. Deißenberger, E. Welz, R. Drescher, I. Krummenacher, R. D. Dewhurst, B. Engels and H. Braunschweig, Angew. Chem., Int. Ed., 2019, 58, 1842.

32 J. Böhnke, T. Dellermann, M. A. Celik, I. Krummenacher, R. D. Dewhurst, S. Demeshko, W. C. Ewing, K. Hammond, M. Heß, E. Bill, E. Welz, M. Röhr, R. Mitrić, B. Engels, F. Meyer and H. Braunschweig, Nat. Commun., 2018, 9, 1197. 33 M. Arrowsmith, J. Böhnke, H. Braunschweig, M. A. Celik, C. Claes, W. C. Ewing, I. Krummenacher, K. Lubitz and C. Schneider, Angew. Chem., Int. Ed., 2016, 55, 11271.

34 T. Peymann, C. B. Knobler and M. F. Hawthorne, Chem. Commun., 1999, 2039. 